\title{
The Fragmentation and Consolidation of International Systems: Erratum
}

\author{
Stuart J. Kaufman
}

Arrow leader lines in two of the maps in the Spring 1997 issue of International Organization (volume 51, No. 2, pp. 173-208) are not legible in printed copies. Although the maps are still usable, we reprint them here for greater clarity. Please substitute the following for Figure 5 on page 189 and figure 6 on page 190.

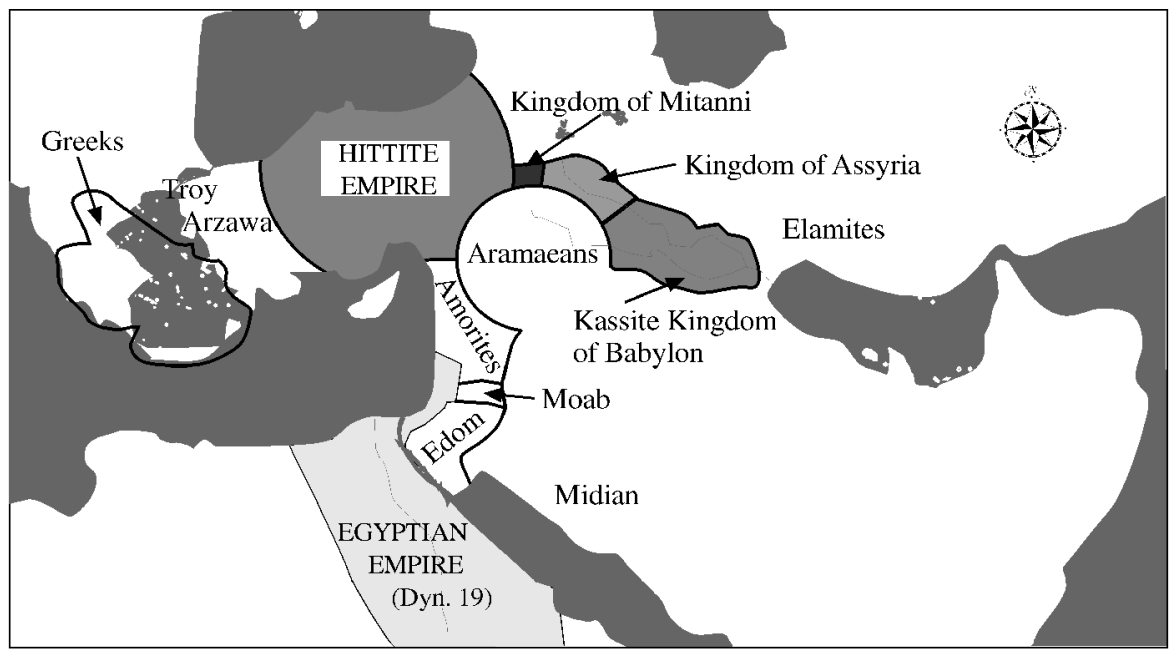

Source: McEvedy 1967, 33. Reproduced by permission of Penguin Books Ltd.

FIGURE 5. Amarna period states, circa 1300 B.C. 


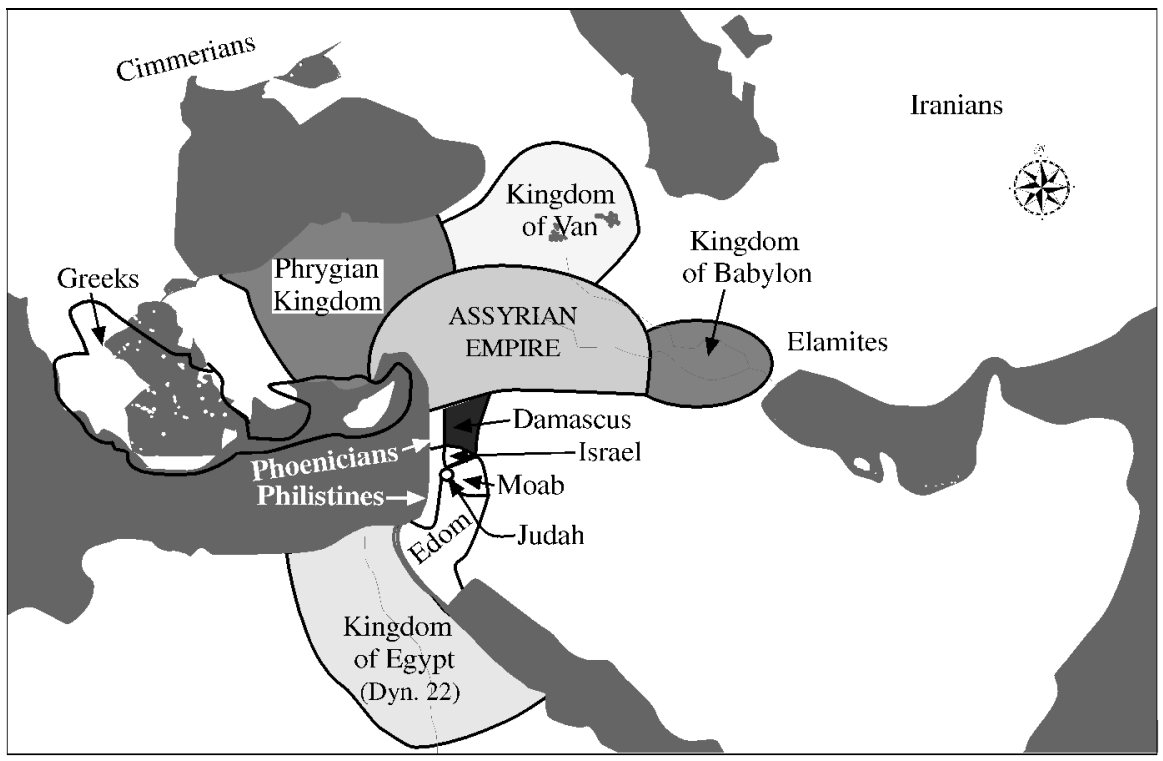

Source: McEvedy 1967, 43. Reproduced by permission of Penguin Books Ltd.

FIGURE 6. Biblical period empires, circa 825 B.C. 